\title{
Qualidade do ensino de graduação: concepções de docentes pesquisadores
}

\author{
Sandra Regina Soares \\ Maria Isabel Cunha
}

Resumo: O texto expõe parte dos resultados de uma pesquisa, de abordagem qualitativa, que buscou compreender o papel da relação entre ensino e pesquisa nas representações acerca de qualidade do ensino de graduação de dezenove professores de cursos de graduação, pesquisadores experientes, que atuam simultaneamente na pós-graduação stricto sensu de uma universidade pública. Inicia com uma reflexão sobre o conceito de qualidade do ensino superior e sobre o ensino com pesquisa. Destaca, entre as evidências do estudo, a falta de clareza sobre esse conceito, a falta de problematização acerca da formação e do perfil de profissional que desenvolvem ou gostariam de desenvolver, a quase inexistência de lugar para o ensino com pesquisa na graduação, apesar da expertise dos depoentes em pesquisa. Aspectos que denotam a prevalência de um estilo de ser professor e de uma cultura institucional que contribuem para a permanência da pedagogia universitária na invisibilidade e para a instalação processual, sem negociação, da perspectiva de qualidade produtivista.

Palavras-chave: Qualidade do ensino superior. Docência universitária. Ensino com pesquisa.

\section{Teaching quality of graduation: conceptions of faculty researchers}

Abstract: This text exposes part of the results of a survey of qualitative approach which aims to understand the role of the relationship between teaching and research in the representations about teaching quality of graduate courses. It involves nineteen teachers of the courses who are experienced researchers and work simultaneously in the stricto sensu post- graduate studies at a public University. It begins with a reflection on the concept of quality in higher education and on teaching with research. It highlights, among the evidence from the study: lack of clarity on this concept; lack of questioning about the training and the professional profile which develop or would like to develop; an almost inexistence of teaching with research in graduate courses, despite the expertise of the subjects in research. These aspects reflect the prevalence of a style of teaching and of an institutional culture which contribute to the permanence of the university pedagogy on invisibility and the installation procedure without negotiation, from the perspective of quality production.

Key words: Quality of higher education. University teaching. Teaching with research. 


\section{Considerações iniciais}

A reflexão sobre a qualidade do ensino na universidade é uma tarefa inadiável para gestores, pesquisadores e docentes, especialmente quando se considera a sua missão de formar profissionais para atuarem num cenário de incerteza e supercomplexidade caracterizado, dentre outros aspectos, por: abundância de dados, conhecimento ou bases teóricas conflitantes, em todos os campos profissionais, que obriga sejam feitas escolhas bem fundamentadas e justificadas; grau de exigência e consciência crescente de seus direitos, por parte dos usuários dos serviços profissionais, instituindo assim uma relação profissionalcliente que exige, além de competência técnica, competências emocionais e atitudinais baseadas em valores éticos, e desafia o autoconhecimento e a reflexão dos profissionais (BARNETT, 2005).

O cenário de incerteza e supercomplexidade é inerente à denominada sociedade do conhecimento, que tem como base o desenvolvimento e a circulação da informação e o entretenimento eletrônico, computadorizado e digital. Nessa sociedade, a economia é, principalmente, baseada no conhecimento "[...] num contexto em que cada vez mais pessoas com educação elevada trabalham no campo das ideias, da comunicação, das vendas, do marketing, da assessoria, da consultoria, do turismo, da organização de eventos, etc." (HARGREAVES, 2004, p. 34). Nessa perspectiva, o conhecimento, a criatividade e a invenção são intrínsecos a tudo que as pessoas fazem.

A inclusão, nessa sociedade, dos diferentes segmentos sociais pressupõe a ampliação do nível de escolaridade e de competência cognitiva da população de cada país. Como afirma Giddens (1998 apud HARGREAVES, 2004, p. 38-39) "o melhoramento da educação e da formação é essencial, particularmente para os grupos pobres [...] o investimento na educação é hoje um imperativo governamental, uma base fundamental para a redistribuição de oportunidades".

Em atenção à sociedade do conhecimento, a educação superior tende a ser assumida como um bem público (UNESCO, 1999) e um direito social, cuja função primordial é a formação de cidadãos capazes de construir uma sociedade mais justa e aberta, mediante um processo de ensino-aprendizagem promotor de análise crítica e visão prospectiva, baseado na vinculação com a sociedade e em atividades de criação intelectual científica, técnica e humanística. Em outras palavras, como meio de transformação social, desenvolvimento sustentável e de inserção competente dos países no cenário internacional. Em consonância com tal tendência, organizações econômicas e órgãos governamentais, em todo o mundo, investem na educação superior (HARGREAVES, 2004).

No Brasil, o Plano Nacional de Educação (BRASIL, 2000) estabelece a meta de elevar de $12 \%$ para, pelo menos, $30 \%$, até 2010 , a oferta de educação superior para jovens da faixa etária de 18 a 24 anos. Preconiza, ainda, a criação de políticas de facilitação do acesso, em igualdade de condições, de jovens oriundos de camadas antes discriminadas nesse nível de ensino, historicamente elitista. Dentre essas políticas, se destacam o REUNI ${ }^{1}$, o ProUni ${ }^{2}$ e a Lei de $\operatorname{cotas}^{3}$.

\footnotetext{
${ }^{1}$ Programa de Apoio ao Plano de Reestruturação e Expansão das Universidades Federais - REUNI, lançado pelo Governo Federal, em 2007, oportunizou, a ampliação das instituições federais de ensino superior, que
} 
Sem dúvida, essas políticas vêm contribuindo para uma significativa mudança no perfil da educação superior introduzindo a qualidade social com a inclusão de jovens e adultos oriundos de camadas sociais até então excluídas desse nível de ensino. Entretanto, a despeito do seu caráter antielitista, a expansão da matrícula não é suficiente para garantir a qualidade efetiva do ensino na era da sociedade do conhecimento.

Conforme Hargreaves (2004), a solução não está em assegurar-se mais educação nas formas atualmente realizadas, centradas na inculcação de conhecimentos existentes, mas em promover-se ensino e aprendizagem capazes de desenvolver as competências cognitivas, sociais e emocionais que contribuam para o trabalho criativo, investigativo, crítico e colaborativo e ético dos futuros profissionais. Assim, além do acesso à informação, é fundamental o desenvolvimento da capacidade das pessoas de processá-la, ressignificá-la, pois "A sociedade do conhecimento é uma sociedade da aprendizagem." (HARGREAVES, 2004, p. 37)

A despeito desses desafios, a universidade, salvo honrosas exceções, segue privilegiando o ensino iluminista, essencialmente intelectualista, abstrato, centrado na transmissão de conhecimentos dogmatizados mediante aulas magistrais, desconectado de uma reflexão sobre a vida dos estudantes e da prática profissional para a qual estão sendo formados. Um ensino que privilegia a cabeça cheia e não a cabeça bem feita, como registra Edgar Morin (2006). Subjacente a esse ensino está uma concepção de estudante como receptor passivo, subalterno e de professor como detentor do saber.

Em reação a esse ensino, típico de uma universidade elitista, processualmente vem se afirmando o neotecnicismo, que consiste na tendência de negar o valor dos saberes acumulados, dos conhecimentos das áreas de humanidades, que passam a ser vistos como arcaicos, desatualizados, sem sentido. Em contrapartida, verifica-se uma ênfase no conhecimento utilitário, pragmático, fast food, voltado para o mercado e destituído de qualquer reflexão crítica. Essa perspectiva, que se pretende inovadora, aposta na introdução de recursos tecnológicos para tornar as aulas mais atrativas.

Embora pareçam conflitantes, as duas concepções de ensino possuem muitos pontos comuns, especialmente: a dissociação entre a preservação dos saberes e a construção de conhecimentos, a desarticulação entre pensar, sentir e agir; a separação entre cognição e atitudes e valores; o ensino transmissivo e o papel de espectador atribuído ao estudante, alienado do seu processo formativo.

passaram de 43, com 148 campi, em 2002 para 59, com 274 campi, em 2012, com previsão de chegar a 63, com 321 campi, em 2014.

${ }^{2}$ Programa Universidade para Todos - Lei 11.096/2005 (BRASIL, 2005) cuja finalidade é conceder bolsas de estudos em graduação, integrais e parciais, em instituições privadas de ensino superior a jovens oriundos do ensino médio em escola da rede pública ou de escolas privadas na condição de bolsistas integrais, a portadores de deficiências e a professores da rede publica de ensino que buscam uma formação em nível superior.

3 Lei No 10.558, de 13 de novembro de 2002 (BRASIL, 2002) que cria o Programa Diversidade na Universidade, e dá outras providências, no âmbito do Ministério da Educação, com a finalidade de implementar e avaliar estratégias para a promoção do acesso ao ensino superior de pessoas pertencentes a grupos socialmente desfavorecidos, especialmente dos afrodescendentes e dos indígenas brasileiros. Os estabelecimentos separam um percentual de vagas para os alunos, que podem concorrer como cotistas, desde que se enquadrem nos critérios estabelecidos, que podem variar de universidade para universidade, e apresentem um nível mínimo de desempenho no processo seletivo exigido pelos cursos aos quais eles estão concorrendo. 
A inovação do ensino numa perspectiva crítica e transformadora, sintonizada com a emergente sociedade do conhecimento, caracteriza-se, dentre outros aspectos, pela introdução na aula da complexidade do real e da incerteza, apostando numa relação dialógica entre a teoria e a prática do campo profissional objeto da formação; pelo exercício do espírito crítico e investigativo dos estudantes, em outros termos da problematização do conhecimento e das práticas; ênfase no trabalho dos conhecimentos de forma interdisciplinar, estabelecendo pontos de conexão entre eles e atribuindo significados próprios relacionados aos problemas da prática que se propõem enfrentar; a participação ativa dos estudantes na reelaboração do conhecimento e a ressignificação de atitudes e valores mediante a reflexão.

Essas características colocam em evidência a importância da pesquisa como eixo do processo formativo dos futuros profissionais, em função do seu potencial de: suscitar a superação da aula tradicional copiada; transformar os estudantes em sujeitos da relação pedagógica, a partir do seu engajamento em todas as etapas do processo; oportunizar, aos atores do processo ensino-aprendizagem, lidar com a incerteza, improvisação e contradição, tomar decisões e aprender a aprender (MORAES, 2004); de estabelecer uma relação complementar entre teoria, questionamento e prática (BARREIRO, 2004). Em síntese, a utilização de tal metodologia seria uma possibilidade de viabilizar um ensino de qualidade, na perspectiva de formar cidadãos e profissionais com competência técnica, política e ética no contexto de incerteza e supercomplexidade.

Considerando-se que a indissociabilidade entre ensino, pesquisa e extensão é um princípio organizacional da instituição universitária, definido constitucionalmente, e que a distingue de outras instituições que promovem o ensino superior, era esperado que a pesquisa integrasse, de forma sistemática, o ensino nos cursos de graduação. Experiências pontuais nesse sentido podem ser localizadas no Brasil desde a década de 1930, entretanto, a partir de 1964, no regime dos militares, o lócus privilegiado para a pesquisa passou a ser a pósgraduação stricto sensu, configurando-se, como enfatiza Paoli (1988), uma separação organizacional segundo a qual competia à pós-graduação a produção do conhecimento pela pesquisa e, à graduação, o consumo reprodutivista desse conhecimento.

A despeito dessa realidade, naturalizou-se a ideia de que a expertise em pesquisa seria condição básica e suficiente para a qualidade da docência universitária. Em sintonia com tal ideia, a formação do docente universitário, quando é referida nos documentos legais, como a Lei de Diretrizes e Bases da Educação Nacional (BRASIL, 1996), o Plano Nacional de Educação, restringe-se àquela oportunizada em cursos de pos-graduação stricto sensu, que se orienta para a pesquisa de um recorte do conhecimento do seu campo disciplinar e não contempla as questões da pedagogia universitária.

Neste estudo, nosso interesse foi compreender o papel da relação entre ensino e pesquisa nas representações sobre qualidade do ensino de graduação de dezenove professores de cursos de graduação, pesquisadores experientes, que atuam simultaneamente na pósgraduação stricto sensu de uma universidade pública, multicampi, do estado da Bahia. A opção por participantes com essas características nos permitiria analisar, a partir de dados empíricos, a contribuição da experiência em pesquisa para a melhoria da qualidade do ensino universitário e para a inovação pedagógica mediante o ensino com pesquisa. 
A pesquisa, de natureza qualitativa, recolheu os dados mediante a entrevista semiestruturada, os quais foram tratados com base na análise de conteúdo do tipo temática (BARDIN, 1977).

\section{Concepções de qualidade do ensino}

O conceito qualidade do ensino, conforme enfatiza Demo (1990), possui uma dimensão formal, que remete à natureza científica, lógica, técnica, analítica dos produtos gerados no interior da universidade, e uma dimensão política que se refere à qualidade do cidadão e do profissional que aí se desenvolve. A dimensão política "Reporta-se não somente à relevância social dos produtos científicos (uso em sociedade), mas, sobretudo à atuação do cientista como ator político." (DEMO, p. 64). Em outros termos, faz referência à capacidade do profissional formado pela universidade, de contribuir para a (re)construção da sociedade e de si, numa perspectiva da práxis, naturalmente dentro de circunstâncias determinadas. Tal dimensão, essencial para a universidade, dificilmente se expressa em "indicadores" quantificáveis, pois

Como a qualidade política não é característica prévia, dada, material, mas algo politicamente construído, não se avaliam produtos, mas processos. [...] Supõe a formação histórica de um sujeito social, capaz de tomar consciência crítica e de formular/realizar projeto próprio de desenvolvimento (DEMO, 1990, p. 66).

Depreende-se aqui que o cerne do conceito de qualidade do ensino é a formação científica e política dos profissionais que a universidade desenvolve, e que sua conquista pressupõe uma reflexão coletiva sobre o projeto político-pedagógico capaz de contribuir nessa direção.

A qualidade do ensino, naturalmente, resulta da combinação de um conjunto de elementos intimamente relacionados dentre os quais se destacam, sobretudo, as características e preparação dos discentes e docentes, a natureza dos programas e métodos de ensino, a relação existente entre a investigação e o ensino, a adequação das instalações físicas e dos equipamentos, o clima institucional das relações humanas em que se desenvolve o processo de ensino e aprendizagem envolvendo valores, atitudes e motivações em que tem lugar o processo de ensino/aprendizagem (ICED, 1987 apud BENEDITO; FERRER; FERRERES, 1995).

Entretanto, existem diferentes perspectivas de se conceber a qualidade, mesmo tendo em conta os elementos anteriormente apontados, as quais expressam interesses e pontos de vista dos indivíduos e grupos acerca dos ideais de sociedade do presente e do futuro. Assim,

Uma educação de qualidade pode significar tanto aquela que possibilita o domínio eficaz dos conteúdos previstos nos planos como aquela que possibilita a aquisição de uma cultura científica ou literária ou aquela que desenvolve a máxima capacidade técnica para servir ao sistema produtivo; ou ainda, aquela que promove o espírito crítico e fortalece o compromisso para transformar a realidade social (MOROSINI, 2008, p. 278).

Grosso modo, na atualidade se delineiam duas grandes acepções desse conceito multidimensional, uma centrada na transformação dos processos e outra, de natureza produtivista, focada na relação custo-benefício, como veremos a seguir. 


\section{Qualidade do ensino como transformação}

$O$ conceito de qualidade do ensino como transformação filia-se à perspectiva, assumida por muitos estudos (ALMEIDA; PIMENTA, 2009; BARNETT, 2005; LAMARRA, 2010; VIEIRA et al., 2009) e adotada como marco desta pesquisa, que associa qualidade à transformação de concepções e práticas de ensinar e de aprender. Evidencia a necessidade da criação na universidade de uma nova cultura acadêmica nos cursos de graduação que contemple, dentre outros aspectos:

[...] o direito do acesso à formação que garanta aos estudantes o desenvolvimento de uma postura frente ao saber, que supere a especialização estreita, problematize as informações e garanta a sua formação como cidadão e profissional cientista compromissado com a aplicação do conhecimento em prol da melhoria da qualidade de vida de toda a sociedade; que possibilite o desenvolvimento do pensamento autônomo, substituindo a simples transmissão do conhecimento pelo engajamento dos estudantes; por um processo que permita ao estudante interrogar o conhecimento elaborado, pensar e pensar criticamente; que enseje a resolução de problemas; estimule a discussão, desenvolva metodologias de busca e de construção de conhecimento (ensinar com pesquisa); que confronte os conhecimentos elaborados e as pesquisas com a realidade; mobilize visões inter e transdisciplinares sobre os fenômenos e aponte e possibilite a solução de problemas sociais (ensinar com extensão) (ALMEIDA; PIMENTA, 2009, p. 17).

Assim, qualidade do ensino é compreendida como tarefa educativa, essencialmente, voltada para a transformação dos sujeitos, mediante o desenvolvimento de capacidades cognitivas e atitudinais e a garantia dos recursos necessários para que essa transformação se processe:

El "valor añadido" es una medida de cualidad en términos del grado en que la experiencia educativa incremente el conocimiento, las capacidades y las destrezas de los estudiantes na toma de decisiones que afectan a su transformación, que -a su vez- proporciona la oportunidad de ampliar sus posibilidades de participar en los procesos que lo afectan (la confianza en sí mismo, el pensamiento crítico, etc.) (LAMARRA, 2010, p. 54).

A perspectiva da qualidade como transformação pressupõe a adoção de uma pedagogia universitária emancipatória, crítica, geradora de mudanças profundas nos docentes, discentes e na cultura acadêmica. Colocar em relevo tal pedagogia não significa optar pelo caminho da padronização das formas de ensinar, nem da incorporação acrítica de metodologias pretensamente inovadoras, mas sim de afirmar a necessidade de se assumir balizas de natureza ética, epistemológica e político-pedagógica para a busca permanente dessa qualidade do ensino. Vieira et al. (2009) formulam oito princípios para a pedagogia universitária que podem ser assumidos como critérios de qualidade do ensino superior numa perspectiva transformadora: intencionalidade, transparência, coerência, reflexividade, relevância, democraticidade, autodireção e criatividade/inovação. O princípio da intencionalidade desafia o docente a formular com clareza os pressupostos e finalidades do seu plano de trabalho, para a disciplina/componente curricular, de forma a integrar as dimensões científica, cultural, técnica/profissionalizante, pessoal e social. O princípio da transparência afirma a importância da publicização desses pressupostos e finalidades, dos processos metodológicos, com vistas à facilitação da aprendizagem significativa, e dos 
parâmetros de avaliação adotados. O princípio da coerência implica a premência da sintonia entre as intenções declaradas, os conteúdos disciplinares e os caminhos adotados para sua concretização na prática pedagógica. O princípio da reflexividade desafia o docente a promover sistematicamente uma reflexão crítica sobre a sua ação pedagógica, seus pressupostos e finalidades, o papel da disciplina no currículo e sua relação com a realidade sócio-profissional imprescindível para a busca permanente da coerência referida. O princípio da relevância coloca, como cerne da prática educativa, linguagens e saberes mais significativos para a construção da identidade profissional, objeto da formação, a partir da articulação entre as expectativas, necessidades, ritmos e interesses diferenciados dos estudantes e o contato investigativo e crítico com o contexto sócio-profissional. O princípio da democraticidade indica que a prática pedagógica se "assenta em valores de uma cidadania democrática: sentido de justiça, respeito pela diferença, liberdade de pensamento e expressão, comunicação e debate de ideias, negociação de decisões, colaboração e inter-ajuda." (VIEIRA et al., 2009, p. 20). O principio da autodireção enfatiza o sentido da prática pedagógica de promoção da autogestão da aprendizagem, da auto-estima e autoconfiança dos estudantes. Por fim, o princípio da criatividade/inovação orienta uma ação pedagógica que

[...] estimula processos de compreensão e intervenção, com implicações profissionais e sociais, promovendo uma interpretação pessoal e uma visão pluri/inter/transdisciplinar do conhecimento e da realidade, capacidades de pesquisa e de resolução de problemas, desenvolvimento de projectos pessoais, capacidades de intervenção no contexto profissional e atitudes de abertura à inovação (VIEIRA et al., 2009, p. 20).

Cunha (2011) contribui para a discussão acerca da qualidade do ensino na perspectiva da transformação formulando seis indicadores: tomar o caráter provisório do conhecimento; assumir a mobilização dos estudantes; estimular o protagonismo do estudante; incluir racionalidades distintas no trato do conteúdo; assumir a relação da prática com a teoria; desenvolver capacidades sociais dos estudantes. Esse conjunto de critérios de avaliação da qualidade do ensino tem como pressupostos uma visão de conhecimento científico como produção humana, datada, situada e perpassada por tensões, valores, interesses; uma visão de ensino comprometida com a aprendizagem reconstrutiva, crítica, autoral, calcada na práxis e na transformação da sociedade; uma visão de ensino mais preocupada com o desenvolvimento de competências cognitivas, atitudinais e sociais do que com a aquisição de uma quantidade expressiva de conhecimentos. A assunção de tais indicadores convoca uma ruptura epistemológica e metodológica, por parte do docente, impossível de acontecer sem investimentos na sua formação pedagógica.

\section{Qualidade do ensino centrada no produto}

A visão de qualidade centrada no produto e na produtividade tem como critério de avaliação a quantidade, o tempo e o custo do que a universidade produz. Assim, como enfatiza Chaú (2001, p. 184), “[...] a pergunta pela produtividade não indaga: o que se produz, como se produz, para que ou para quem se produz, mas opera uma inversão tipicamente ideológica da qualidade em quantidade." 
Nessa visão de qualidade, a docência, entendida como transmissão rápida de conhecimentos apresentados em materiais de fácil leitura para os estudantes e destituída de metodologias ativas que estimulem o pensamento crítico e autoral, não é considerada na avaliação da 'produtividade' e, portanto, não é percebida como fundamental para a qualidade. Esvaziada a docência, a graduação, no nosso país, vem sendo reduzida a "[...] um segundo grau avançado para a formação rápida e barata de mão-de-obra com diploma universitário." (CHAUÍ, 2001, p. 38). Em contrapartida, a pós-graduação passa a ser “[...] o funil seletivo de docentes e estudantes, aos quais é reservada a verdadeira formação universitária.” (p. 38). Consequentemente, os títulos de graduação e pós-graduação stricto sensu fornecidos pela universidade se configuram como graus hierárquicos de separação entre esses níveis de ensino, ao invés de serem estruturados integralmente e dessa forma contribuírem para a transformação da formação e para a emancipação dos atores envolvidos.

\section{Ensino com pesquisa como estratégia inovadora para a qualidade}

Com vimos anteriormente, a concepção de qualidade do ensino como transformação implica a adoção de práticas pedagógicas inovadoras que, conforme Lucarelli (2010, p. 12), são "[...] experiencias que representan una ruptura con las prácticas habituales en el aula universitaria y que son gestadas y llevadas a cabo de manera protagónica por los docentes."

A ruptura e o protagonismo docente são os elementos mais característicos da inovação voltada para a solução de situações de aula com vistas à aprendizagem dos estudantes. Nesse sentido, as práticas pedagógicas inovadoras envolvem, necessariamente, além do protagonismo docente, o protagonismo discente, base da aprendizagem construtiva.

As práticas pedagógicas inovadoras são dinamizadas e potencializadas pela implementação da relação teoria e prática de natureza dialética, na qual os dois componentes assumem igual importância e se retroalimentam.

Assim,

[...] la aplicación de conceptos teóricos a situaciones particulares no implica reproducir taxativamente lo enunciado por esos conceptos, sino aceptar la especificidad de cada caso y de cada vía del conocimiento, lo que supone reconocer que las relaciones entre las esferas teórica y práctica son parciales, fragmentarias y complementarias (LUCARELLI, 2010, p. 14$15)$.

Nessa relação, verifica-se intensa orientação para a aprendizagem significativa mediante a observação, busca de informação, realização de pesquisa que permita sintetizar, identificar, derivar, retrabalhar conteúdos conceituais, procedimentais e atitudinais adquiridos pelo estudante. A dúvida e a crítica são assumidas como elementos fundantes do processo ensino-aprendizagem.

O ensino com pesquisa é a forma mais avançada e inovadora de relação entre teoria e prática, concorrendo, portanto, para a qualidade concebida como transformação. Baseia-se na problematização, questionamento e criatividade suscitando um engajamento ativo dos estudantes em atividades de investigação e, portanto, contribuindo para processo de aprender a aprender, aprender a compreender e intervir na realidade. Não se trata de transformar o professor e os estudantes em pesquisadores especializados. Não se articula à lógica de 
produção de conhecimentos novos, nem contribui "para prestígio na comunidade científica dos formadores que as encorajam." (PERRENOUD, 1993, p. 125). Não se caracteriza, portanto, como ensino para pesquisa desenvolvido nos programas de pós-graduação stricto sensu, no qual se espera, por parte do pós-graduando, a garantia do rigor metodológico na produção de dados e interpretações, a elaboração de um conhecimento ou interpretação original que contribua para o avanço da área de conhecimento em que está inserido (PAOLI, 1988). Orienta-se, fundamentalmente, por uma preocupação didático-pedagógica relacionada aos objetivos da formação. Assim, "Sem nunca esmorecer e garantir o rigor do processo, o formador deve ter o espírito tão aberto quanto os formandos em relação aos resultados dessa tentativa." (p. 125).

O potencial dessa perspectiva de ensino para a construção da autonomia profissional se explica

[...] porque a investigação induz necessariamente a uma relação ativa com os saberes e com a realidade de que pretendem dar conta. Por que para conduzir uma observação estruturada, um inquérito, uma experiência é necessário manusear conceitos, variáveis, hipóteses, 'objetos teóricos' de uma maneira mais íntima e mais exigente do que em trabalhos práticos de outra natureza (PERRENOUD, 1993, p. 120-121).

Explica-se, ainda, conforme o autor, porque ao oportunizar o contato dos estudantes com áreas incertas do saber e o cotejamento entre conceitos e dados observáveis, a investigação suscita: a escuta e o olhar mais atento, além das aparências; a relativização das evidências do senso comum; uma visão mais analítica e fina da realidade; e desafia-os a tomar decisões fundamentadas, refletidas, tal como é desejável que procedam no exercício da profissão.

Assumir o ensino com pesquisa pressupõe, portanto, uma ressignificação da concepção de aprendizagem:

Sin embargo, el aprendizaje es el nexo fundamental entre docencia y investigación. Se trata de un proceso compartido en estas dos funciones [...]. La docencia y la investigación presentan una correlación en la medida en que están relacionadas, esto es, cuando lo que se relaciona son dos aspectos de la misma actividad: el aprendizaje (BREW; BROUD, 1995 apud HUGHES, 2008, p. 33).

\section{Qualidade do ensino e sua relação com a pesquisa na visão dos participantes}

Apesar da dificuldade de explicitar ideias mais sistematizadas acerca da qualidade do ensino, a quase totalidade dos participantes vincula esse conceito a algum atributo do docente. Dentre os atributos, os mais referidos foram: compromisso, dedicação, responsabilidade, competência técnica e domínio do conteúdo. O destaque aos três primeiros aspectos sinaliza uma preocupação com a postura ética e política do professor frente à universidade pública e ao ensino de graduação. Para alguns, esses atributos se expressam na disposição do professor de assumir o regime de dedicação exclusiva e desenvolver as três atividades básicas da universidade (ensino, pesquisa e extensão), na seriedade e respeito aos estudantes no desempenho das tarefas de ensino. Esse posicionamento, descolado de uma reflexão sobre o contexto institucional de intensificação e burocratização do trabalho dos docentes da educação superior, em especial, dos que atuam também em programas de pós-graduação stricto sensu, 
como é o caso dos nossos participantes, parece assumir uma conotação moralizadora e pouco reflexiva que tende a responsabilizar exclusivamente o professor que se distancia do que é esperado. Ademais, embora esses atributos sejam importantes para a concretização da qualidade do ensino, são absolutamente insuficientes se dissociados do investimento na transformação do processo ensino-aprendizagem, dissociação que se insinua nos dois últimos atributos mencionados: competência técnica e domínio do conteúdo.

A competência técnica e o domínio do conteúdo da matéria por parte do professor parecem se associar a uma perspectiva tecnicista de utilização de recursos que possam tornar mais visual e atrativa suas aulas expositivas. O foco da prática docente parece ser o ensino centrado na transmissão, que pode envolver a retomada dos conteúdos, se necessário o atendimento individual, mas sempre no sentido de esclarecer os conteúdos ensinados. Tais atributos, mencionados pela maioria dos colaboradores, não apontam para a transformação da prática pedagógica, não indicam a ruptura com as práticas centradas na transmissão e reprodução.

A qualidade do ensino é também vinculada às condições físicas e materiais dos cursos na visão de oito participantes. Tal associação é mais forte entre os participantes que atuam nos campi situados nas cidades do interior, evidenciando que a criação desses nem sempre resultou de um planejamento estratégico envolvendo a garantia de condições essenciais para funcionarem. Dentre essas condições, alguns destacam a ausência de equipamentos de climatização das salas, o que gera muita dispersão dos estudantes, laboratórios, equipamentos de projeção, bibliotecas equipadas. Tais elementos, a nosso ver, se configuram como condições importantes para a qualidade do ensino, entretanto, na concepção de qualidade como transformação, outros elementos são igualmente fundamentais, como número de estudantes por sala, existência de programas e bolsas de atividades de extensão, pesquisa e monitoria de ensino, transparência na gestão, etc.

A qualidade do ensino é associada, na menção de sete participantes, a atributos dos estudantes como: compromisso, dedicação aos estudos, honestidade, disponibilidade, iniciativa frente aos desafios, vontade de aceitar o novo e de aprender com os erros. Conforme os depoimentos, esses atributos não se relacionam a conquistas que seriam realizadas a partir da trajetória dos estudantes no curso, e sim a comportamentos que deveriam fazer parte do repertório discente desde seu ingresso. A expectativa de estudantes ideais, prontos para receber os ensinamentos, estudantes que "não dão trabalho" aos professores, aproxima, vários participantes, de uma visão elitista de universidade e, ao mesmo tempo, distancia-os de uma perspectiva de profissionalização da docência universitária, na medida em que revelam desconhecimento ou desconsideração quanto aos saberes didático-pedagógicos, base da profissionalidade docente, que os permitiria compreender os estudantes reais e como eles aprendem e ajudá-los, efetivamente, a construírem saberes e atitudes imprescindíveis para sua atuação profissional. Saberes e atitudes que vão muito além da acumulação de conhecimentos, mas envolvem primordialmente uma formação ética capaz de assegurar que a "[...] construção, a socialização e os usos da ciência e da técnica, sejam colocados sob o foco de reflexões e de crítica, para que não percam seu valor essencial de bases e instrumentos do desenvolvimento humano integral" (DIAS SOBRINHO, 2009, p. 25).

Diante do reconhecimento de que a maioria dos estudantes está longe desse perfil idealizado e da compreensão de que o professor não tem possibilidade de alterar tal situação, 
alguns participantes verbalizam a expectativa de uma seleção mais exigente para garantir o ingresso na universidade de estudantes mais competentes: “[...] em teoria a gente já deveria encontrar os alunos com esse tipo de conhecimento, para mim a falta de estrutura e a falta de conhecimentos anteriores (dos estudantes) são os grandes comprometedores da qualidade." (P8- Urbanismo).

O ingresso na universidade de estudantes de origem popular parece ser valorizado por dois participantes quando defendem a implantação de um serviço permanente de apoio psicopedagógico aos estudantes. Tal proposta não é destituída de importância, mas ela não substitui o trabalho do professor que, mediante práticas pedagógicas inovadoras, precisa investir no desenvolvimento integral dos estudantes, assumindo, prioritariamente, o papel de mediador, provocador da reflexão, pensamento crítico e capacidade de manusear informações, interpretar, relacionar, criar, argumentar, trabalhar em equipe, enfim, incorporando a aprendizagem significativa de saberes e atitudes e a formação de profissionais autônomos como o cerne de sua práxis.

O ensino com pesquisa não emerge explicitamente na reflexão dos participantes sobre a qualidade do ensino, entretanto, instigados a expressarem seus pontos de vista sobre o assunto, revelam compreendê-lo como: sinônimo de socialização dos resultados da pesquisa do professor e de outros pesquisadores; vinculado à atividade de Iniciação Cientifica; envolvendo a participação do conjunto dos estudantes da turma; associado à preleção sobre a importância da pesquisa e ao fornecimento de orientações metodológicas.

A totalidade dos participantes afirma desenvolver ensino com pesquisa apresentando aos estudantes resultados de pesquisas suas ou de outrem para fundamentar, contextualizar e enriquecer suas aulas. Um participante do curso de Agronomia informa, também, que o conjunto dos estudantes do componente curricular que ministra realiza visitas aos contextos onde o professor desenvolve sua pesquisa. Configura-se aqui, no dizer de Healey (2008), a docência impulsionada pela investigação, na qual o professor desenvolve a relação entre ensino e pesquisa mediante a apresentação aos estudantes, preferencialmente, de resultados de pesquisa. Nessa situação, os estudantes são colocados frente à pesquisa na condição de espectadores.

O ensino com pesquisa vinculado à atividade de Iniciação Científica foi referido por metade dos participantes. Essa atividade, na qual alguns estudantes selecionados se integram ao grupo de pesquisa do professor e participam ou acompanham todas as etapas do processo de investigação, é percebida como importante para o desenvolvimento de habilidades investigativas nos estudantes e para que eles sejam estimulados a seguirem estudos pósgraduados. Essa forma de estabelecer a relação entre ensino e pesquisa embora seja muito importante, é elitista, se assumida isoladamente, porque acessível a um número restrito de estudantes (no máximo três por professor). Ademais, não desafia o docente a transformar suas práticas pedagógicas, consolida a dissociação entre ensino e pesquisa. Todos os alunos merecem um percurso de formação no qual a pesquisa seja o fio condutor do processo educativo.

O ensino com pesquisa envolvendo o conjunto dos estudantes da turma foi mencionado por apenas quatro participantes. Ao se referirem a essa prática educativa informam ter a intenção de desenvolver nos futuros profissionais: atitude investigativa, atitude de questionamento e de valorização das origens dos estudantes, compromisso com a 
comunidade na medida em que as pesquisas servem de base para ações de extensão dos estudantes da graduação e da pós-graduação. Tal perspectiva, embora não tenha sido detalhadamente descrita pelos depoentes, remete à concepção de docência baseada na investigação (HEALEY, 2008), na qual os estudantes são também investigadores, e o plano de ensino se desenrola mediante a problematização e investigação do contexto da prática pelos estudantes. Aproxima-se da dimensão política da qualidade, referida por Demo (1990), se compreendemos a pesquisa como um diálogo inteligente com a realidade, calcado na atitude de questionamento crítico, comprometido com a emancipação e a mudança. Outros três depoentes declaram se aproximar do ensino com pesquisa nas atividades de laboratório e nas visitas de campo cujas observações analisadas devem se traduzir em um artigo por parte dos estudantes. Entretanto, um deles reconhece que a lógica que vem presidindo a experimentação no laboratório, em geral, é a da reprodução.

$\mathrm{O}$ ensino com pesquisa associado à preleção sobre a importância da pesquisa e ao fornecimento de teorizações metodológicas é referido por quatro participantes. Na perspectiva da preleção, verbalizam em sala, por exemplo, que a profissão, para a qual os estudantes estão se formando, não tem natureza puramente prática, e que eles precisam entrar no universo da pesquisa; durante sua exposição sobre o assunto, sempre alertam que os conteúdos resultam de pesquisa. $\mathrm{O}$ ensino com pesquisa associado ao fornecimento de teorizações metodológicas aparece na visão de um participante que utiliza, como estratégia de avaliação (para obtenção de nota), a produção de um projeto de pesquisa no qual, com a ajuda do professor, os estudantes deverão delimitar um objeto de pesquisa. Essa perspectiva se aproxima da docência orientada para a investigação, na qual os estudantes aprendem os processos utilizados na pesquisa e o plano da disciplina valoriza tanto o ensino do conteúdo disciplinar quanto o ensino da metodologia da pesquisa. Nessa situação, os "professores pretendem suscitar um ethos investigador através de sua docência." (HEALEY, 2008, p. 97). Entretanto, os estudantes se situam frente à pesquisa na condição de espectadores.

\section{À guisa de conclusão}

A realização desta pesquisa possibilitou evidenciar aspectos fundamentais para a compreensão das concepções e práticas acerca de qualidade do ensino e sua relação com a pesquisa de docentes/pesquisadores universitários.

Um primeiro aspecto que ressalta da análise do conjunto das contribuições dos colaboradores da pesquisa é a falta de clareza sobre o conceito qualidade do ensino. Quando instados a se posicionar sobre a questão, suas proposições se referem a determinadas condições para que a qualidade aconteça, mas não a critérios ou indicadores da sua concretização. Ademais, suas respostas vão se articulando num processo de idas e vindas, como se estivessem tateando num terreno ainda pouco explorado, distante de suas reflexões do cotidiano.

Esses elementos sugerem uma frágil compreensão e explicitação, para si próprios, da intencionalidade do ensino que desenvolvem na graduação. Como sabemos, a ação educativa é, necessariamente, intencional, quer se tenha ou não consciência das intenções que a impulsionam. Intencionalidade que orienta a direção da ação pedagógica em consonância com as representações acerca das necessidades da sociedade e com os pressupostos de natureza 
científica, cultural, técnica/profissionalizante, pessoal e política dos docentes. A escassa e assistemática análise sobre a intencionalidade do ensino, sobre o que significa desenvolvê-lo com qualidade, entre outros aspectos, distancia os participantes da concepção de qualidade como transformação, inovação, e concorre para a reprodução de práticas educativas assentadas nos modelos dos antigos mestres. Revela uma subestimação do ensino na graduação, provavelmente em função da crença difundida de que a competência científica e a capacidade de comunicar bastam para ser professor. Subestimação que é reforçada e naturalizada no contexto atual de

[...] escolarização da graduação, e mesmo da pós-graduação, ou seja, com a transformação do ensino num conjunto de técnicas de transmissão de informações e conhecimentos. Não permitindo o surgimento de sujeitos do conhecimento, não propiciando a aparição de pesquisadores a partir do próprio ensino, não fazendo da docência nosso modo fundamental de trabalhar academicamente, evidentemente cria-se o problema da relação entre ensino e pesquisa (CHAUI, 2001 p. 172).

Entretanto, a complexidade da docência se impõe quando o ensino tradicional não responde às necessidades contemporâneas e desafia, como registra Reimão (2001), a passagem do modelo pedagógico magistro-centrado para o modelo sóciocentrado que, por sua vez, coloca novas exigências para o docente que só podem ser apropriadas e enfrentadas de forma protagonista e inovadora a partir da reflexão, individual e entre os pares, sobre a qualidade do ensino.

Um segundo aspecto que chama a atenção nas proposições acerca da qualidade do ensino dos depoentes é a falta de problematização, por parte da maioria, acerca da formação profissional que desenvolvem ou gostariam de desenvolver. O perfil de profissional a ser formado não aparece como indicador de qualidade. Apenas um participante faz referência à necessidade do professor, de conhecer o projeto político-pedagógico do curso. A formação profissional é associada principalmente a acúmulo de teorias, salvo raras exceções, prevalecendo a fragmentação disciplinar, a hiperespecialização descolada da reflexão sobre a formação do profissional desenvolvida no curso.

Um terceiro aspecto que se destaca é a quase inexistência de lugar para o ensino com pesquisa na graduação, conforme se depreende do depoimento da maioria dos participantes, apesar da expertise em pesquisa que possuem. Essa evidência denota, de um lado, a prevalência de um estilo de ser professor universitário, naturalmente com variações, centrado no ensino e, não na aprendizagem, na transmissão de conhecimentos disciplinares dogmatizados, e não na construção de saberes e atitudes para a formação de profissionais com competência técnica, estética, ética e política. Que concebe qualidade do ensino associada ao domínio do conteúdo e de técnicas, e não à transformação das práticas educativas na perspectiva do protagonismo docente e discente. Estilo construído a partir da vivência com antigos mestres, valorizados pela sapiência e capacidade de erudição, e preservado pela ausência de formação inicial e continuada para o exercício da docência nesse nível de ensino, o que dificulta a assunção do ensino com pesquisa, pois, para viabilizá-lo, é preciso que o ponto de partida seja a compreensão da docência e dos saberes didático-pedagógicos indispensáveis para gerar aprendizagens baseadas na participação ativa de todos os estudantes. 
A quase inexistência de lugar para o ensino com pesquisa na graduação denota traços importantes de uma cultura acadêmica e institucional contraditória que quantifica e atribui mais prestígio ao trabalho do professor relacionado à pesquisa (publicações, apresentação de trabalhos, dissertações e teses que orienta, conferências que profere, financiamentos externos conquistados mediante projetos de pesquisa), mas não democratiza o acesso à pesquisa a todos os docentes (praticamente restrito aos docentes que atuam na pós-graduação), nem garante as condições materiais e de tempo para o exercício da pesquisa diante da excessiva carga de horas aula na graduação, gerando a impressão (expressa por alguns dos nossos depoentes) de que o ensino é mais valorizado pela instituição e o sentimento de que o ensino rouba o tempo da pesquisa e da publicação. Essas e outras contradições concorrem para uma tensão entre as atividades de ensino e pesquisa, para o desenvolvimento de uma forma de esquizofrenia no professor, ora é docente (ministra aula, nem sempre com prazer provavelmente pela falta de apropriação de saberes didático-pedagógicos), ora é pesquisador (atividade que faz com prazer nos espaços e tempos possíveis e com base numa formação obtida nos programas de pós-graduação stricto sensu).

Enfim, tanto esse estilo de ser professor quanto a cultura acadêmica institucional contribuem para a permanência da pedagogia universitária na invisibilidade e para o não investimento institucional e pessoal no desenvolvimento profissional docente. Criam, portanto, condições favoráveis para a instalação processual, sem qualquer discussão ou negociação entre os atores envolvidos no ensino superior, da perspectiva de qualidade produtivista.

\section{Referências}

ALMEIDA, Maria Isabel de; PIMENTA, Selma Garrido. Pedagogia universitária: valorizando o ensino e a docência na universidade de São Paulo. In: PIMENTA, Selma Garrido; ALMEIDA, Maria Isabel de (Orgs.). Pedagogia universitária. São Paulo: EDUSP, 2009. p. 13-37.

BARDIN, L. Análise de conteúdo. Lisboa: Edições 70, 1977.

BARREIRO, Cristhianny Bento. Questionamento sistemático: alicerce na reconstrução dos conhecimentos. In: MORAES, Roque; LIMA, Valderez Marina do Rosário. Pesquisa em sala de aula. Tendências para a educação em novos tempos. Porto Alegre: EDIPUCRS, 2004. p. 171-188.

BARNETT, Ronald. A Universidade em uma era de supercomplexidade. São Paulo: Ed. Anhembi Morumbi, 2005.

BENEDITO, V.; FERRER, V.; FERRERES, V. La formación universitaria a debate. Barcelona: Universitat de Barcelona, 1995.

BRASIL. Presidência da República. Casa Civil. Lei no. 11.096, de 13 de junho de 2005. Institui o Programa Universidade para Todos- ProUni, regula a atuação de entidades beneficentes de assistência social no ensino superior altera a lei no. 10891 e dá outras providências. Diário Oficial da União, Brasília, 14 jan. 2005. 
BRASIL. Presidência da República. Casa Civil. Lei no.10.558, de 13 de novembro de 2002. Cria o Programa Diversidade na Universidade, e dá outras providências. Diário Oficial da União, Brasília, 14 nov. 2002.

BRASIL. Ministério da Educação. Plano Nacional de Educação. Brasília, 2000.

BRASIL. Ministério da Educação. Lei n. 9.394, de 20 de dezembro de 1996. Estabelece as Diretrizes e Bases da Educação Nacional. Brasília, DF: MEC, 1996.

CHAUÍ, Marilena. Escritos sobre a universidade. São Paulo: Editora UNESP, 2001.

CUNHA, Maria Isabel da; Qualidade do ensino na educação superior e a indissociablidade do ensino, pesquisa e extensão: os desafios conceituais e práticos num contexto de democratização. In: SEMINÁRIO INTERNACIONAL QUALIDADE NA EDUCAÇÃO SUPERIOR: Indicadores e Desafios, 9., 2011. Atas... Porto Alegre: REDE SULBRASILEIRA DE INVESTIGADORES DA EDUCAÇÃO SUPERIOR - RIES, 2011.

DEMO, Pedro. Universidade e qualidade: indagação em torno da qualidade formal e política da formação universitária. Educação Brasileira, Brasília, v. 12, n. 25, p. 61-81, 1990.

DIAS SOBRINHO, José. Professor universitário: contextos, problemas e oportunidades. In: CUNHA, M. I.; SOARES, S. R.; RIBEIRO, M. L. (Orgs.). Docência universitária: profissionalização e prática educativa. Feira de Santana: UEFS Editora, 2009. p. 15-32.

HARGREAVES, Andy. $O$ ensino na sociedade do conhecimento: educação na era da insegurança. Porto Alegre: Artmed, 2004.

HEALEY, Mick.Vínculos entre docencia e investigación: reflexión en torno a los espacios disciplinares y el papel del aprendizaje basado en la indagación. In: BARNETT, Ronald (Ed.). Para una transformación de la universidad: nuevas relaciones entre investigación, saber y docencia. Barcelona: Octaedro, 2008. p. 93-137.

HUGHES, Mark. Los mitos en torno a las relaciones entre investigación y docencia en las universidades. Barnett, Ronald. Para una transformación de la universidad. Nuevas relaciones entre investigación, saber e docencia. Barcelona: Octaedro, 2008.

LAMARRA, Noberto Fernandez. Hacia una nueva agenda: a de la educación superior en América Latina. Mexico, D.F.: Asociación Nacional de Universidades e Instituciones de Educación Superior, Dirección de Medios Editoriales, 2010.

LUCARELLI, Elisa. La articulación teoría práctica y las experiencias de innovación en las aulas de la UNS. In: LUCARELLI, Elisa; MALET, Ana Maria (Comp.). Universidad y prácticas de innovación pedagógica. Estudio de casos en la UNS. Buenos Aires: Jorge Baudino Ediciones, 2010.

MORAES, Roque. Educar pela pesquisa: exercício de aprender a aprender. In: MORAES, Roque; LIMA, Valderez Marina do Rosário. Pesquisa em sala de aula. Tendências para a educação em novos tempos. Porto Alegre: EDIPUCRS, 2004. p.127-142.

MORIN, Edgar. A cabeça bem-feita. Repensar a reforma, reformar o pensamento. Rio de Janeiro: Bertrand Brasil, 2006. 
MOROSINI, Marília. Internacionalização da educação superior e qualidade. In: AUDY. J.L. Inovação e qualidade. Porto Alegre: EDIPUCRS, 2008.

PAOLI, Niuvenius Junqueira. O princípio da indissociabilidade do ensino e da pesquisa. Cadernos CEDES, São Paulo, n. 22, 1988.

PERRENOUD, Philippe. Práticas pedagógicas, profissão docente e formação. Perspectivas sociológicas. Lisboa: Publicações Dom Quixote, 1993.

REIMÃO, Cassiano. Apresentação do colóquio. In: REIMÃO, Cassiano (Org.). A formação pedagógica dos professores do ensino superior. Lisboa: Edições Colibri, 2001. p. 19-25.

UNESCO. Política de mudança e desenvolvimento no ensino superior. Rio de Janeiro: Garamond, 1999.

VIEIRA, Flavia; SILVA, José Luis; ALMEIDA, Judite. Transformar a pedagogia na universidade: possibilidades e constrangimentos. In: VIEIRA, Flávia. (Org.). Transformar a pedagogia na universidade. Narrativas da prática. Portugal: De Facto Editores, 2009. p. 1738 .

Sandra Regina Soares - Universidade do Estado da Bahia Salvador | BA | Brasil. Contato: ssoares@uneb.br

Maria Isabel Cunha - Universidade do Valo do Rio dos Sinos Porto Alegre | RS | Brasil. Contato: mabel@unisinos.br 